\title{
Purification of Proteins From Cell-Culture Medium or Cell-Lysate by High-Speed Counter-Current Chromatography Using Cross-Axis Coil Planet Centrifuge
}

\author{
Yoichi Shibusawa ${ }^{*}, \mathrm{a}$ and Yoichiro Ito $^{\mathrm{b}}$ \\ ${ }^{a}$ Division of Pharmaceutical and Biomedical Analysis, School of Pharmacy, Tokyo University of Pharmacy and Life \\ Science, 1432-1 Horinouchi Hachioji, Tokyo 192-0392, Japan \\ ${ }^{b}$ Center for Biochemistry and Biophysics, National Heart, Lung, and Blood Institute, National Institutes of Health, Be- \\ thesda, MD 20892-8014, USA
}

\begin{abstract}
This review describes protein purifications from cell culture medium or cell-lysate by high speed countercurrent chromatography using the cross-axis coil planet centrifuge. Purifications were performed using aqueous two phase systems composed of polyethylene glycols and dextrans.
\end{abstract}

\section{INTRODUCTION}

Aqueous-aqueous polymer phase systems for the partitioning of biological macromolecules were first established by Albertsson in the 1950s [1]. Among many types of aqueous-aqueous polymer phase systems available, polyethylene glycol (PEG)-dextran and PEG-potassium phosphate systems have been most commonly used for the partition of biological samples. Using these solvent systems, several different approaches have been made for performing purification of biological samples, such as single step partitioning, repetitive batch extraction, counter-current distribution (CCD) [2, 3] and counter-current chromatography (CCC) [4].

CCC is essentially a form of liquid-liquid partition chromatography in which the stationary phase is retained in the column with the aid of gravity or a centrifugal force field [47]. This method has been termed after two classic partition techniques, that is, the CCD and liquid chromatography. The flow-through centrifuge systems $[8,9]$ have been developed for performing CCC and provide various advantages for continuous elution through a rotating column. In the early $1980 \mathrm{~s}$ a great advance in the CCC technology was made by the discovery of a new hydrodynamic phenomenon in a rotating coiled tube [10], which provided a basis for developing a highly efficient CCC system called high-speed CCC (HSCCC) [11]. The cross-axis coil planet centrifuge (CPC) with the column holders shifted laterally along the holder shaft enables retention of the stationary phase of aqueousaqueous two-phase systems, with the aid of the laterally acting strong centrifugal field $[12,13]$.

With PEG-potassium phosphate systems, the cross-axis $\mathrm{CPC}$ has been successfully used for the separations of a variety of protein samples, including a mixture of cytochrome c, myoglobin, ovalbumin and hemoglobin [14], human plasma lipoproteins (HDL, LDL and VLDL) [15-17], cholinesterase

*Address correspondence to this author at the Division of Pharmaceutical and Biomedical Analysis, School of Pharmacy, Tokyo University of Pharmacy and Life Science 1432-1 Horinouchi, Hachioji, Tokyo 192-0392, Japan; Tel: +81-42-676-4544; Fax: +81-42-676-4542;

E-mail: sibusawa@ps.toyaku.ac.jp from human serum [18], lactic acid dehydrogenase from bovine heart crude extract $[19,20]$, alcohol dehydrogenase from bovine liver crude extract [21], various recombinant enzymes $[22,23]$ from E. coli cell-lysate. Single-strand DNA binding protein was also purified by one step operation of CCC from an $E$. coli cell-lysate with a combined use of partition and precipitation method [24]. Because of the high salts concentration of the PEG-potassium phosphate and PEG-ammonium sulfate systems, however, these aqueous two-phase systems are not suitable for the separation of proteins which are easily precipitating out by these salts. In this case, we have to use other types of aqueous-aqueous polymer two phase systems composed of PEG and dextran which form two phases without an addition of salts. In the past the CCC separations of basic histones, serum proteins [25], and profilin-actin complex from crude Acanthamoeba extract [23] were performed using PEGdextran two-phase systems. We have demonstrated the purification of glucosyltransferase (GTF) from Streptococcus mutans cell-lysate and $S$. sobrinus culture medium [26, 27] using a 7.7\% PEG 8000-4.0\% dextran T500 solvent system. After HSCCC purification, these polymers were removed from CCC fractions using a hydroxyapatite chromatography. However, due to irreversible adsorption onto the hydroxyapatite (HA) column packings, GTF was lost about $10 \%$ from $S$. mutans samples and $54 \%$ from $S$. sobrinus samples. Recently, we have demonstrated that the use of low molecular weight polymers such as dextran T40 and PEG 3350 will facilitate the removal of these polymers from collected fractions by ultrafiltration without losing target proteins [28].

The purification of maltose binding protein tagged histone deacetylase (MBP-HDAC), which would be precipitated out due to a high salt concentration of the two-phase system such as $16 \%$ PEG $1000-12.5 \%$ potassium phosphate system, was performed by cross-axis CPC using the solvent system composed of relatively low molecular weight of polymers which are easily removed from the $\mathrm{CCC}$ fractions by ultrafiltration [29].

The details of the GTF and MBP-HDAC purification by counter-current chromatography using the cross-axis CPC with aqueous two phase systems will be described in this chapter. 


\section{PREPARATION OF PROTEIN SAMPLES}

\subsection{Preparation of Streptococcus Sobrinus Culture Me- dium and $S$. mutans Cell-Lysate}

Glucosyltransferase (GTF) from Streptococcus sobrinus and $S$. mutans were prepared described elsewhere [26, 27]. The cell culture medium or cell-lysate were used for the protein samples.

\subsection{Preparation of Escherichia coli Cell-Lysate}

A maltose binding protein tagged histone deacetylase (MBP-HDAC) was prepared as described by Borra et al. [30].

\section{MEASUREMENT OF ENZYMATIC ACTIVITY}

\subsection{Glucosyltransferase Enzymatic Activity}

Glucosyltransferase (GTF) enzymatic activity was estimated from the amount of water-insoluble glucan (WIG) produced from sucrose by GTF [31]. In addition, for determination of the specific activity of purified GTF, an aliquot of WIG was measured by the phenol-sulfate method [32, 33].

\subsection{Histone Deacetylase Activity}

The HPLC-based deacetylation assay was employed as described by Borra [30, 34]. The HPLC analysis was performed using a LC system and a Chromolith Performance RP-18e column (100 x 4.6 mm I.D.) described elsewhere [29].

\section{AQUEOUS TWO PHASE SYSTEMS}

4.1. Preparation of PEG 8000-Dextran T 500 Aqueous Two-Phase Solvent Systems for Concentration of Culture Media of Streptococus sobrinus

In order to concentrate a large volume $(500 \mathrm{ml})$ of culture medium into $10 \mathrm{ml}$ of sample solution of counter-current chromatography (CCC) without losing the GTF, three different polymer phase systems were prepared: $4.4,6.0$ and $7.5 \%$ PEG 8000-1.0, 3.0 and 6.0\% dextran T500, each having different volume ratio between the upper and the lower phases (Table 1).

Table 1. Upper and Lower Volume Ratio of PEG 8000Dextran T500 Aqueous Polymer Two-Phase Systems with Different Polymer Concentrations

\begin{tabular}{|c|c|c|c|}
\hline $\begin{array}{c}\text { PEG 8000 } \\
(\mathbf{w} / \mathbf{w} \%)\end{array}$ & $\begin{array}{c}\text { dextran T500 } \\
(\mathbf{w} / \mathbf{w} \%)\end{array}$ & $\begin{array}{c}\text { Upper Phase } \\
(\mathbf{v} / \mathbf{v} \%)\end{array}$ & $\begin{array}{c}\text { Lower Phase } \\
(\mathbf{v} / \mathbf{v} \%)\end{array}$ \\
\hline \hline 7.5 & 1.0 & 97.6 & 2.4 \\
\hline 7.5 & 3.0 & 83.3 & 16.7 \\
\hline 7.5 & 6.0 & 71.7 & 28.3 \\
\hline 6.0 & 1.0 & 93.3 & 6.7 \\
\hline 6.0 & 3.0 & 78.3 & 21.7 \\
\hline 6.0 & 6.0 & 63.3 & 36.7 \\
\hline 4.4 & 1.0 & single & phase \\
\hline 4.4 & 3.0 & 75.0 & 25.0 \\
\hline 4.4 & 6.0 & 55.0 & 45.0 \\
\hline
\end{tabular}

\subsection{Conventional Aqueous Polymer Two Phase Systems}

Aqueous two-phase solvent systems were prepared by modifying the standard polymer phase systems used for the protein separation [23, 35]. The PEG 8000-dextran T500 systems were prepared by dissolving $44 \mathrm{~g}$ of PEG 8000 and $60 \mathrm{~g}$ of dextran T500 in $10 \mathrm{mM}$ potassium phosphate buffer to make the total mass of $1000 \mathrm{~g}$. The $\mathrm{pH}$ of the solvent system was adjusted to the desired value between 4.6 and 9.2. The solvent mixture was thoroughly equilibrated in a separatory funnel at room temperature. The two phases, consisting of the PEG-rich upper phase (UP) and the dextran-rich lower phase (LP), were separated shortly before use. The percent volumes of UP and LP were about 55 and 45\%, respectively.

4.3. Aqueous Two Phase Systems Composed of Relatively Low Molecular Weight of Polyethylene Glycol and Dextran for Protein Separation

The following aqueous two-phase solvent systems were prepared by modifying the standard polymer phase systems used for the protein separation: In order to facilitate removal of the polymers by ultrafiltration after CCC fractionation, low molecular weight of polyethylene glycols (PEGs) and dextrans were used for the two-phase systems as shown in Table 2. For the selection of suitable solvent systems which provide satisfactory retention of the stationary phase, the kinematic viscosity of upper and lower phases of aqueous two-phase systems was determined using a capillary viscometer [36]: Sample solution (upper or lower phase of an aqueous two-phase system) was placed into an Ubbelohde viscometer to measure the time (in second) required for the unit volume of the sample solution to fall down through the capillary. For each polymer system, the kinematic viscosity $\left(\mathrm{mm}^{2} / \mathrm{s}\right)$ of the upper and the lower phases was calculated and listed in Table 2 .

Table 2. Volume Ratio of Upper and Lower Phases of Several Polyethylene Glycol (PEG)-Dextran T40 Aqueous Two-Phase Systems

\begin{tabular}{|c|c|c|c|}
\hline \multirow{2}{*}{$\begin{array}{l}\text { Aqueous-Aqueous Two-Phase } \\
\text { Systems }^{*}\end{array}$} & \multirow{2}{*}{$\begin{array}{c}\begin{array}{c}\text { Volume } \\
\text { Ratio }\end{array} \\
(\mathrm{UP} / \mathrm{LP})^{* *}\end{array}$} & \multicolumn{2}{|c|}{$\begin{array}{l}\text { Kinematic Viscosity } \\
\qquad\left(\mathrm{mm}^{2} / \mathbf{s}\right)\end{array}$} \\
\hline & & $\mathbf{U} \mathbf{P}^{* *}$ & $\mathbf{L} \mathbf{P}^{* *}$ \\
\hline $17.5 \%$ PEG $1000-20.0 \%$ dextran T10 & 1.6 & 6.8 & high viscosity \\
\hline $15.0 \%$ PEG $1540-17.5 \%$ dextran T10 & 1.7 & 6.8 & high viscosity \\
\hline $12.5 \%$ PEG $2000-15.0 \%$ dextran T10 & 1.7 & 6.3 & 35 \\
\hline $12.5 \%$ PEG $3350-15.0 \%$ dextran T10 & 1.7 & 7.9 & 40 \\
\hline $12.5 \%$ PEG $4000-15.0 \%$ dextran T10 & 1.7 & 7.6 & 33 \\
\hline $10.0 \%$ PEG $8000-12.5 \%$ dextran T10 & 1.9 & 12.0 & 18 \\
\hline $15.0 \%$ PEG $1000-15.0 \%$ dextran T40 & 1.6 & 4.4 & high viscosity \\
\hline $10.0 \%$ PEG $1540-15.0 \%$ dextran T40 & 0.9 & 4.5 & high viscosity \\
\hline $10.0 \%$ PEG $2000-15.0 \%$ dextran T40 & 1.1 & 4.7 & high viscosity \\
\hline $7.5 \%$ PEG 3350-10.0\% dextran T40 & 1.1 & 5.5 & 20 \\
\hline $7.5 \%$ PEG $4000-10.0 \%$ dextran T40 & 1.3 & 5.0 & 22 \\
\hline $5.0 \%$ PEG $8000-12.5 \%$ dextran T40 & 1.0 & 6.7 & 24 \\
\hline
\end{tabular}




\section{PARTITION COEFFICIENT VALUES OF PRO- TEINS}

5.1. Partition Coefficient of Streptococus mutans CellLysate and Glucosyltransferase in the Conventional Aqueous Two Phase Systems

Optimization of the solvent composition to adjust the partition coefficient of the glucosyltransferase $(\mathrm{GTF})\left(\mathrm{K}_{\mathrm{GTF}}\right)$ is essential for successful separation. This can be done spectrophotometrically by a simple test tube experiment as described elsewhere [26]. For the determination of partition coefficient of $S$. mutans cell-lysate $\left(\mathrm{K}_{\mathrm{SM}}\right)$, the total UV at $220 \mathrm{~nm}$ of the proteins in both upper and lower phases were measured with a UV-1200 spectrophotometer (Shimadzu, Kyoto, Japan). On the other hand, the $\mathrm{K}_{\mathrm{GTF}}$ in the lysate was determined from the enzyme activity in each phase.

Both the $\mathrm{K}_{\mathrm{SM}}$ and $\mathrm{K}_{\mathrm{GTF}}$ were examined in aqueous polymer two-phase systems of both 16\% (w/w) PEG 1000-12.5\% (w/w) potassium phosphate system and in $4.4 \%$ (w/w) PEG $8000-6.0 \%(\mathrm{w} / \mathrm{w})$ dextran T500 systems at different $\mathrm{pH}$ values. The results showed that GTF and some other protein components in the lysate were precipitated in the PEGphosphate system, whereas proteins were completely dissolved in the PEG-dextran system which were then used for the determination of the $\mathrm{K}_{\mathrm{SM}}$ and $\mathrm{K}_{\mathrm{GTF}}$. $\mathrm{K}_{\mathrm{SM}}$ and $\mathrm{K}_{\mathrm{GTF}}$ were individually measured in the $4.4 \%$ (w/w) PEG $8000-6.0 \%$ (w/w) dextran T500 systems buffered with $10 \mathrm{mM}$ phosphate at various $\mathrm{pH}$ values ranging from 4.6 to 9.2 . Table 3 lists the partition coefficient of each component. As the $\mathrm{pH}$ is increased from 4.6 to 9.2 , the $\mathrm{K}_{\mathrm{SM}}$ values are sharply increased from 0.18 to 1.89 , whereas $\mathrm{K}_{\mathrm{GTF}}$ values measured at different $\mathrm{pHs}$ are below 0.1 indicating that GTF is almost entirely distributed to the dextran-rich lower phase regardless of the $\mathrm{pH}$ of the polymer phase system. This strongly suggests that the unilateral distribution of GTF to the lower phase is caused by a strong affinity between the dextranbinding domain of GTF and dextran molecules in lower phase. The maximum difference between $\mathrm{K}_{\mathrm{SM}}$ and $\mathrm{K}_{\mathrm{GTF}}$ was found at $\mathrm{pH} 9.2$ in this PEG 8000-dextran T500 two-phase system ( $\mathrm{K}_{\mathrm{SM}}$ and $\mathrm{K}_{\mathrm{GTF}}$ were 1.89 and 0.05 , respectively). However, the difference between both $\mathrm{K}$ values is too small for one-step extraction of GTF from SM lysate using this solvent system with a good recovery rate. For an effective purification of GTF, either the extraction repeated with several times or one run of CCC separation may be necessary.

Table 3. Partition Coefficients of $S$. mutans Cell-Lysate and GTF in Phosphate Buffered PEG 8000-Dextran T500 Two-Phase Systems

\begin{tabular}{l|c|c|}
\hline pH of Buffer in Two-Phase System ${ }^{* 1}$ & $\mathbf{K}_{\mathbf{S M}}{ }^{{ }^{* 2}}$ & $\mathbf{K}_{\mathbf{G T F}}{ }^{{ }^{* 3}}$ \\
\hline \hline 9.2 & 1.89 & 0.05 \\
\hline 8.0 & 1.82 & 0.08 \\
\hline 7.0 & 0.88 & 0.03 \\
\hline 6.0 & 0.38 & 0.02 \\
\hline 4.6 & 0.18 & $<0.01$ \\
\hline${ }^{* 1}$ Two-phase system: $4.4 \%$ PEG 8000 and $6 \%$ dextran T500 containing $10 \mathrm{mM}$ potas- \\
sium phosphate buffer. \\
${ }^{* 2} \mathrm{~K}_{\mathrm{SM}}:$ partition coefficient of $S$. mutans cell-lysate. \\
${ }^{* 3} \mathrm{~K}_{\mathrm{GTF}}$ : partition coefficient of GTF.
\end{tabular}

We carried out the purification of GTF from the SM lysate by CCC because of its high efficiency of separation and concentration. 4.4\% (w/w) PEG 8000-6.0\% (w/w) dextran T500 containing $10 \mathrm{mM}$ phosphate buffer ( $\mathrm{pH}$ 9.2) was used as aqueous polymer two-phase system on this CCC separation, and the dextran-rich lower phase was used as a stationary phase. For keeping the optimum condition of viscous stationary phase retention in the column, cross-axis CPC was needed and used centrifugal unit on this CCC separation system.

\subsection{Partition Coefficient of Storeptococus mutans Cell- Lysate and GTF in the Two Phase Systems Composed of Relatively Low Molecular Weight PEGs and Dextran}

Table 4 lists the $\mathrm{K}_{\mathrm{SM}}$ and $\mathrm{K}_{\mathrm{GTF}}$ in the three kinds of twophase systems composed of PEG 3350, 4000 and PEG 8000 with dextran T40 each buffered with $10 \mathrm{mM}$ dipotassium phosphate at $\mathrm{pH}$ 9.0. The $\mathrm{K}_{\mathrm{SM}}$ obtained in these aqueous two-phase systems containing PEG 3350 and PEG 4000 are almost identical. Increasing the molecular weight of PEG from 4000 to 8000 resulted in decrease of $\mathrm{K}_{\mathrm{SM}}$. On the other hand, $\mathrm{K}_{\mathrm{GTF}}$ values obtained from three different aqueous two-phase systems, i.e., 7.5\% PEG 3350-10.0\% dextran T40, 7.5\% PEG 4000-10.0\% dextran T40 and 5.0\% PEG 8000$12.5 \%$ dextran $\mathrm{T} 40$ are $0.11,0.10$ and 0.10 , respectively. Since the retention of the stationary phase greatly depends on the viscosity of the stationary phase, we selected the solvent systems composed of 7.5\% PEG 3350-10.0\% dextran T40-10mM dipotassium phosphate, which has lower viscosity.

Table 4, Partition Coefficient of $S$. mutans Cell-Lysate and GTF in PEG-Dextran Two-Phase Systems

\begin{tabular}{|l|c|c|}
\hline \multicolumn{1}{|c|}{ Aqueous-Aqueous Two-Phase Systems ${ }^{\mathbf{a}}$} & $\mathbf{K}_{\mathbf{S M}}{ }^{\mathbf{b}}$ & $\mathbf{K}_{\mathbf{G T F}}{ }^{\mathbf{c}}$ \\
\hline \hline $5.0 \%$ PEG 8000-12.5\% dextran T40 (pH 9.0) & 0.34 & 0.10 \\
\hline $7.5 \%$ PEG 4000-10.0\% dextran T40 (pH 9.0) & 0.55 & 0.10 \\
\hline $7.5 \%$ PEG 3350-10.0\% dextran T40 (pH 9.0) & 0.56 & 0.11 \\
\hline $7.5 \%$ PEG 3350-10.0\% dextran T40 (pH 8.0) & 0.45 & 0.11 \\
\hline $7.5 \%$ PEG 3350-10.0\% dextran T40 (pH 7.0) & 0.35 & 0.05 \\
\hline $7.5 \%$ PEG 3350-10.0\% dextran T40 (pH 6.0) & 0.30 & 0.05 \\
\hline${ }^{a}$ PEG 3350.4000, 8000-dextran T40-10 mM potassium phosphate buffers.
\end{tabular}

${ }^{2}$ PEG 3350, 4000, 8000-dextran T40-10 mM potassium phosphate buffers.

${ }^{\mathrm{b}} \mathrm{K}_{\mathrm{SM}}$ : partition coefficient of $S$. mutans cell-culture medium.

${ }^{c} \mathrm{~K}_{\mathrm{GTF}}$ : partition coefficient of GTF.

$\mathrm{K}_{\mathrm{SM}}$ and the $\mathrm{K}_{\mathrm{GTF}}$ are also greatly affected by the $\mathrm{pH}$ of the solvent systems. To obtain a large difference of $\mathrm{K}_{\text {lysate }}$ and $\mathrm{K}_{\mathrm{GTF}}$, these values are measured in the 7.5\% PEG 3350$10.0 \%$ dextran T40-10 mM potassium phosphate buffers at $\mathrm{pH}$ 6.0, 7.0, 8.0 and 9.0 (Fig. 1). Both the $\mathrm{K}_{\mathrm{SM}}$ and the $\mathrm{K}_{\mathrm{GTF}}$ values increases as the solvent $\mathrm{pH}$ increases. The largest difference between the $\mathrm{K}_{\mathrm{SM}}$ and $\mathrm{K}_{\mathrm{GTF}}$ is obtained at $\mathrm{pH}$ 9.0. Then the GTF purification was performed with the aqueous two-phase solvent systems composed of 7.5\% PEG 3350$10.0 \%$ dextran T40-10 mM dipotassium phosphate at $\mathrm{pH} 9.0$ by the cross-axis CPC. 


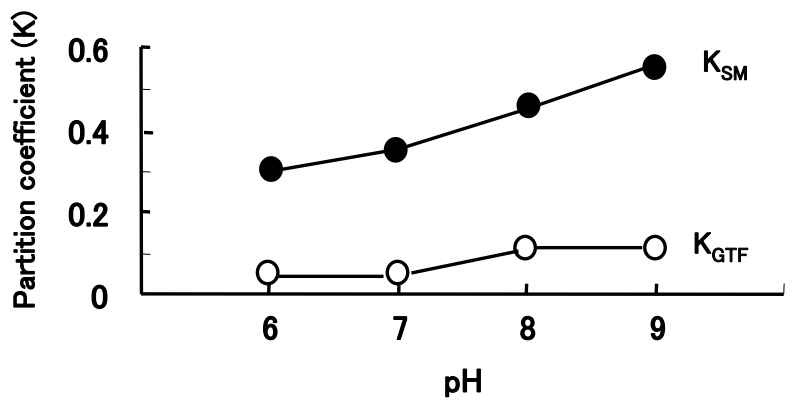

Fig. (1). Effect of pH of two-phase systems on partition coefficient of cell lysate and GTF.

\subsection{Determination of Partition Coefficient of $\boldsymbol{E}$. coli Cell- Lysate and Maltose Binding Protein Tagged Histone Deacetylase}

For the determination of partition coefficient of E. coli cell-lysate $\left(K_{\mathrm{EC}}\right)$, the total $\mathrm{UV}$ at $280 \mathrm{~nm}$ of the proteins in both upper and lower phases were measured with a UV-1200 spectrophotometer. The partition coefficient of maltose binding protein tagged histone deacetylase (MBP-HDAC) $\left(K_{\mathrm{MBP}-}\right.$ HDAC) was determined using purified MBP-HDAC by affinity chromatography.

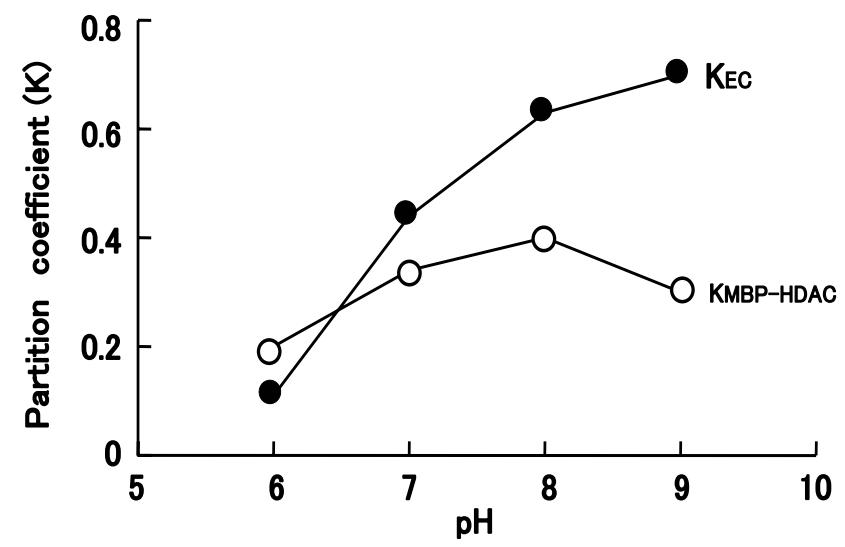

Fig. (2). Effect of $\mathrm{pH}$ of aqueous two-phase systems on the partition coefficients of cell-lysate and MBP-HDAC.

Solvent systems: $7.0 \%$ PEG 3350, 10.0\% dextran T40, $10 \mathrm{mM}$ potassium phosphate buffer at $\mathrm{pH} 6.0,7.0,8.0$ and 9.0.

The $K_{\mathrm{EC}}$, and $K_{\mathrm{MBP}-\mathrm{HDAC}}$ in the aqueous two-phase system composed of $7.0 \%$ PEG 3350 and $10.0 \%$ dextran T40 are also greatly affected by the $\mathrm{pH}$ of the solvent system. To obtain a large difference between $K_{\mathrm{EC}}$ and $\mathrm{K}_{\mathrm{MBP}-\mathrm{HDAC}}$, these $K$ values are measured in the $7.0 \%$ PEG $3350-10.0 \%$ dextran T40-10 mM potassium phosphate buffers at $\mathrm{pH}$ 6.0, 7.0, 8.0 and 9.0. As shown in Fig. (2), the $K_{\mathrm{EC}}$ steadily becomes higher as the solvent $\mathrm{pH}$ increases. Althrough the $K_{\mathrm{MBP}-\mathrm{HDAC}}$ also rises at $\mathrm{pH} 6.0$ to 8.0 , it declines at $\mathrm{pH} 9.0$. The largest difference between $K_{\mathrm{EC}}$ and $K_{\mathrm{MBP}-\mathrm{HDAC}}$ values is obtained at $\mathrm{pH}$ 9.0. Therefore, the MBP-HDAC purification form E. coli cell-lysate was performed with the aqueous two-phase solvent systems composed of 7.0\% PEG 3350-10.0\% dextran T40-10 mM dibasic potassium phosphate at $\mathrm{pH} 9.0$ using the cross-axis CPC.

\section{COUNTER-CURRENT CHROMATOGRAPHY OF PROTEINS USING A CROSS-AXIS COIL PLANET CENTRIFUGE}

\subsection{Apparatus}

The cross-axis coil planet centrifuge (CPC) has a unique feature among the $\mathrm{CPC}$ systems available in that it provides reliable retention of the stationary phase for viscous polymer phase systems. The detailed design of the cross-axis CPC was described elsewhere [37, 38]. The apparatus holds a pair of horizontal rotary shafts, symmetrically mounted one on each side of the rotary frame, at a distance of $10 \mathrm{~cm}$ from the centrifuge axis as shown in Fig. (3). A spool-shaped column holder is mounted on each rotary shaft at an off-center position $10 \mathrm{~cm}$ from its mid-point. The multilayer coil separation column was prepared from a $2.6 \mathrm{~mm}$ I. D. polytetrafluoroethylene (PTFE) tube (Zeus Industrial Products, Raritan, NJ, USA) by winding it onto a $5.0 \mathrm{~cm}$ diameter holder hub, forming three or four layers of left-handed coils between a pair of flanges spaced $5 \mathrm{~cm}$ apart. A pair of columns mounted on the rotary frame was connected in series with a flow tube (PTFE, $0.85 \mathrm{~mm}$ I.D.) resulting in the total capacity of $110 \mathrm{ml}$ or $145 \mathrm{ml}$. The speed of the apparatus is regulated at $400 \mathrm{rpm}$ with a speed control unit (Bodine Electric, Chicago, IL, USA).

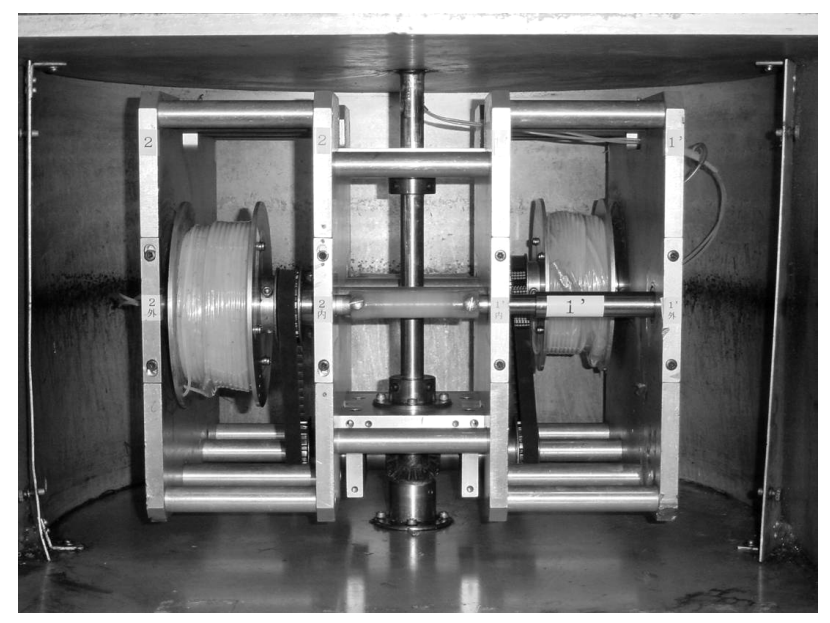

Fig. (3). Photograph of type XL cross-axis coil planet centrifuge.

In each experiment, the $\mathrm{CCC}$ column of the cross-axis CPC was first entirely filled with the dextran-rich lower stationary phase and the sample solution was injected into the column using an EYELA type SV 6000 sample injector (Tokyo Rikakikai, Tokyo, Japan). The PEG-rich upper phase was eluted through the column at a desired flow rate of 0.25 $1.0 \mathrm{ml} / \mathrm{min}$ by an EYELA LP-1100 pump (Tokyo Rikakikai), while the apparatus was rotated at $400 \mathrm{rpm}$. The effluent from the outlet of the column was consinuously monitored with an EYELA UV 9000 absorbance monitor (Tokyo Rikakikai) at $280 \mathrm{~nm}$, and fractionated into test tubes using Advantec CHF 100AA fraction collector (Toyo Seisakusho, Chiba, Japan). Most of the proteins were eluted from the column with the upper PEG-rich upper phase, and the target protein still retained in the lower liquid stationary phase was 
collected by empting the column contents using an EYELA SMP-23 cassette tube pump (Tokyo Rikakikai). Finally, an aliquot of each fraction was diluted with distilled water and the absorbance measured at $280 \mathrm{~nm}$ with a Shimadzu UV1200 spectrophotometer. The enzyme activity of each fraction was also measured by enzymatic assay described above.

\subsection{Purification of Glucosyltransferase from Storeptoco- cus sobrinus Cell-Culture Medium}

\subsubsection{Batch Extraction of Glucosyltransferase from Cul- ture Medium Using Aqueous Polymer Two Phase Systems}

S. sobrinus releases glucosyltransferase (GTF) into the culture medium resulting in excessive dilution of the enzyme. This necessitates careful selection of the method to concentrate the target enzyme from $500 \mathrm{ml}$ to $10 \mathrm{ml}$ or 50 fold without loss of the enzymatic activity. Concentration of GTF with the polymer phase system requires a suitable volume ratio between the two phases, where the volume of the upper phase is much greater than that of the lower dextranrich phase. As shown in Table 1, sets of polymer phase systems with different $\mathrm{PEG} /$ dextran ratios and concentrations were tested to measure the volume ratio between the two phases. The minimum volume ratio of the lower phase of 2.4 (v/v\%) was obtained with 7.5\% PEG 8000-1.0\% dextran T500 aqueous two phase system, and by adding $41.0 \mathrm{~g}$ of PEG 8000 and $5.5 \mathrm{~g}$ of dextran T500 to the $500 \mathrm{ml}$-volume of culture medium, the GTF was concentrated into $12.0 \mathrm{ml}-$ volume of the lower phase (Fig. 4).

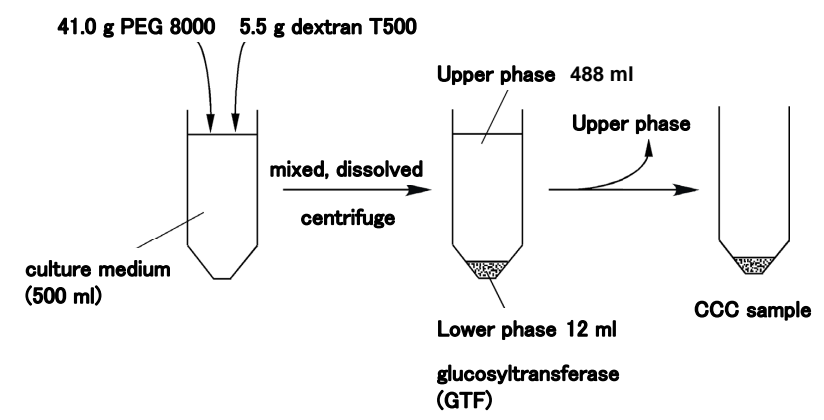

Fig. (4). Schematic presentation of the concentration of GTF in the dextran-rich lower phase by batch extraction using aqueous polymer two-phase system.

\subsubsection{Purification of GTF by Counter-Current Chroma- tography}

Fig. (5) shows a counter-current chromatogram of the concentrated GTF with the cross-axis CPC using 4.4\% (w/w) PEG 8000-6\% (w/w) dextran T500-10 mM dibasic potassium phosphate ( $\mathrm{pH}$ 9.2). The separation was performed at $400 \mathrm{rpm}$ and at a flow-rate of $1.0 \mathrm{ml} / \mathrm{min}$ using the upper phase. After a large peak was eluted in the frs. 35-75, the CCC run was stopped and the equilibrated column content was fractionated by forcing the solvent from the column with air using a peristaltic pump. The solid circles indicate the absorbance at 220 $\mathrm{nm}$ in the eluted upper phase and the open circles those in the stationary lower phase of the column contents. The bar graphs in the chromatogram indicated the GTF enzyme activities which are solely found in frs. 120-129 obtained from the column content. However, these fractions contain high concentrations of dextran T500 which cannot be easily removed by dialysis or ultrafiltration method. To eliminate those high con- centrations of polymers, CCC fractions were diluted with potassium phosphate buffers and subject to the hydroxyapatite chromatography.

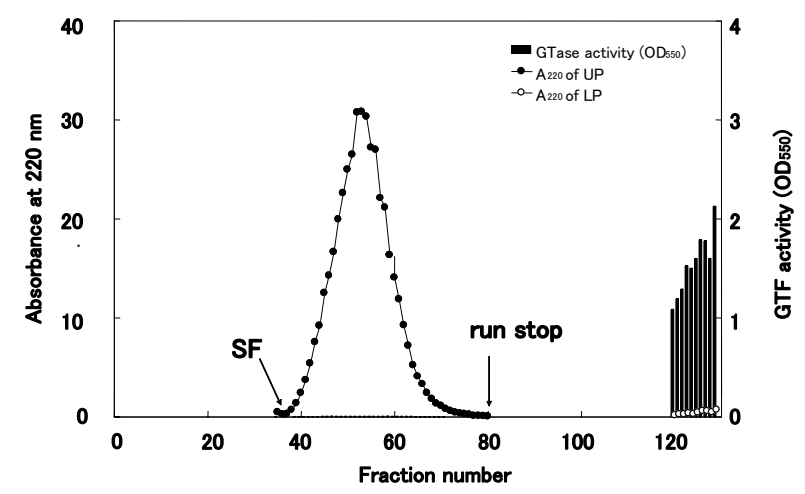

Fig. (5). Counter-current chromatogram of concentrated GTF by batch extraction. CCC conditions: column: a pair of $2.6 \mathrm{~mm}$ I.D. PTFE multilayer coils with a total capacity of $145 \mathrm{~mL}$; sample: $10 \mathrm{~g}$ of lower phase of batch extraction of culture medium containing $7.5 \%$ (w/w) of PEG-8000 and 1.0\% (w/w) of dextran-T500; solvent system: $4.4 \%(\mathrm{w} / \mathrm{w})$ PEG-8000 and $6.0 \%(\mathrm{w} / \mathrm{w})$ dextran-T500 containing $10 \mathrm{mM}$ phosphate buffer ( $\mathrm{pH} 9.2)$; mobile phase: PEG-rich upper phase; flow rate: $1.0 \mathrm{~mL} / \mathrm{min}$; revolution: $400 \mathrm{rpm}$; fractionation: $3.0 \mathrm{~mL} /$ tube; $\mathrm{SF}=$ solvent front.

\subsubsection{Hydroxyapatite Chromatography of CCC Fractions}

Fig. (6) shows a hydroxyapatite chromatogram of CCC fractions. Frs. 120-129 were collected together in the Fig. (5) and diluted with 10 -fold volume of $100 \mathrm{mM}$ potassium phosphate buffer at $\mathrm{pH}$ 7.0. About $300 \mathrm{ml}$-volume of diluted sample solution was loaded onto the hydroxyapatite column (25 $\mathrm{cm} \times 2 \mathrm{~cm}$ I.D.) and eluted stepwise with $150 \mathrm{mM}$ and 500 $\mathrm{mM}$ phosphate buffer. After the elution of polymers with $150 \mathrm{mM}$ phosphate buffer, GTF still remained in the column and was recovered with $500 \mathrm{mM}$ potassium phosphate buffer (frs. 66-90) thus maintaining their enzymatic activities. These fractions containing GTF were dialyzed, concentrated and analyzed by SDS polyacrylamide gel electrophoresis (SDS-PAGE), according to the method of Laemmli [39].

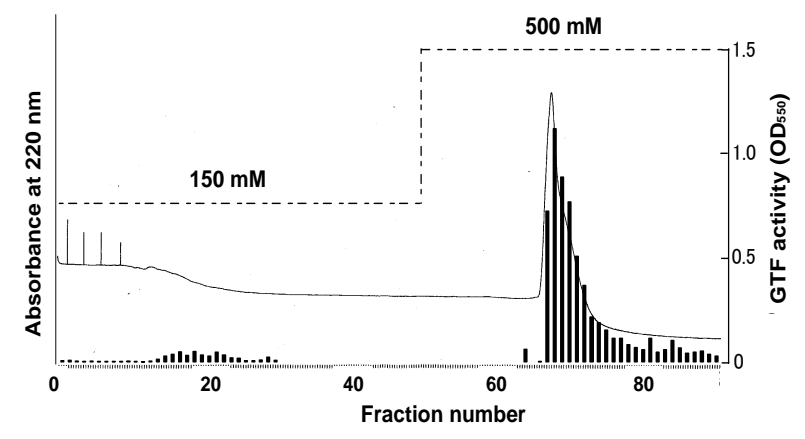

Fig. (6). Elimination of polymers and purification of GTF in the CCC fraction by hydroxyapatite chromatography. Chromatographic conditions: column: Bio-Gel HTP DNA grade hydroxyapatite $(25 \times 2 \mathrm{~cm}$ I.D.); sample: 10 fold diluted CCC fraction corresponding to frs.120129 of Fig. (3); mobile phase: stepwise elution with $150 \mathrm{mM}$ and $500 \mathrm{mM}$ potassium phosphate buffers at $\mathrm{pH} 7.0$; flow rate: 1.0 $\mathrm{mL} / \mathrm{min}$; detection: UV absorbance at $220 \mathrm{~nm}$; fractionation: 3.0 $\mathrm{mL} /$ tube. GTF activity $\left(\mathrm{A}_{550}\right)$ of each fraction is indicated by bar graphs. 
Fig. (7) shows the SDS PAGE profiles of the several samples obtained by the present method (concentration with dextran-rich polymer phase, countercurrent chromatography and hydroxyapatite chromatography). The lower phase of the aqueous polymer two-phase system prepared by adding PEG 8000 and dextran T500 to the culture medium of the S. sobrinus (sample solution) and CCC fractions contained a small amount of GTF corresponding to the molecular weigh of 150 kDa. Frs. 66-90 obtained by hydroxyapatite chromatography (Fig. 6) and 10-fold concentrated fractions clearly produced GTF bands. No other proteins were found in the hydroxyapatite chromatography fraction after purification by CCC.

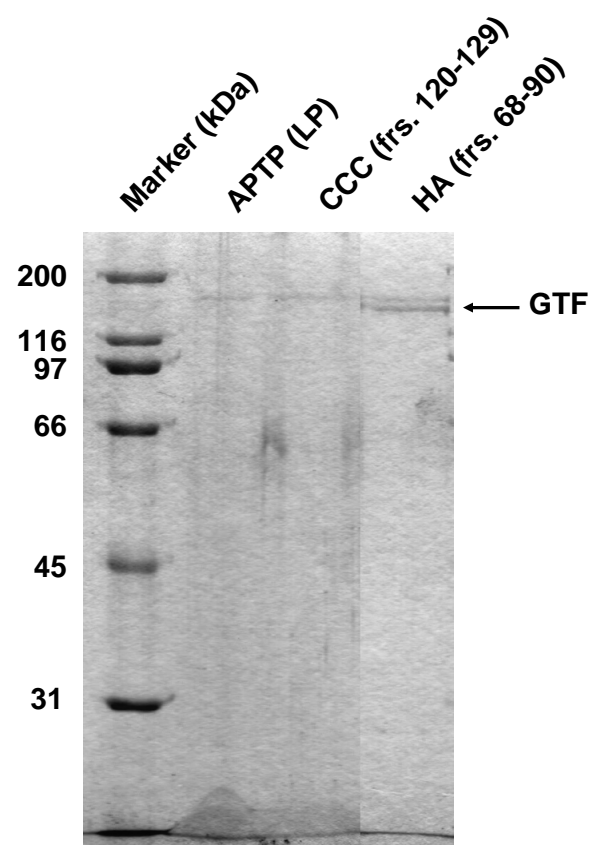

Fig. (7). 10\% SDS polyacrylamide gel electrophoresis profiles of the several purification steps of the GTF.

\subsubsection{Purity and Recovery Rate of GTF After Two Types of Chromatography Steps}

The purity and recovery rate of GTF were estimated at each purification step by the protein quantity and the GTF activities. Table 5 shows the purity and recovery rate of GTF in each fraction after two types of chromatography steps. Through the GTF purification process, the purity of GTF was greatly increased while maintaining a reasonable recovery rate. In the first step of purification by the batch extraction in the aqueous polymer two phase system, the total proteins were decreased about 1/30 compared with those in the culture medium of $S$. sobrinus. After CCC, the recovery of the total activity of GTF was $70 \%$ of that in the culture medium. In the final GTF purity after hydroxyapatite chromatography was increased about 272 times as that in the large amount of culture medium of $S$. sobrinus. We assume that the excellent results of GTF purification in the present method is attained by the combined use of batch extraction, $\mathrm{CCC}$ and hydroxyapatite chromatography.

6.3. Purification of Glucosyltransferase from Streptococcus mutans Cell-Lysate by Counter-Current Chromatography

\subsubsection{Using PEG 8000-Dextran T500 Two Phase System}

Fig. (8) shows the CCC chromatogram where solid circles indicate the absorbance at $220 \mathrm{~nm}$ in the eluted upper

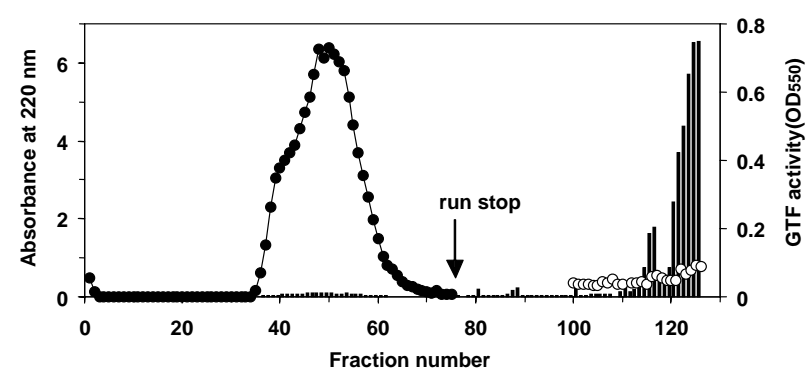

Fig. (8). Separation profile of Streptococcus mutans cell-lysate by CCC using the cross-axis CPC. CCC conditions: column: a pair of $2.6 \mathrm{~mm}$ I.D. PTFE multilayer coils with a total capacity of $145 \mathrm{ml}$; sample: $10 \mathrm{~g}$ of SM cell-lysate containing $0.44 \mathrm{~g}$ of PEG 8000 and $0.6 \mathrm{~g}$ of dextran T500; solvent system: 4.4\% (w/w) PEG 8000 and $6.0 \%(\mathrm{w} / \mathrm{w})$ dextran $\mathrm{T} 500$ containing $10 \mathrm{mM}$ phosphate buffer (9.2); mobile phase: PEG-rich upper phase; flow rate: $1.0 \mathrm{ml} / \mathrm{min}$; revolution: $400 \mathrm{rpm}$; fractionation: $3.0 \mathrm{ml} /$ tube. Following the elution of mobile phase for $225 \mathrm{~min}$ (i.e. up to fr. 75), dextran-rich stationary phase was pushed out from the column by air pressure and fractionated from frs. 76 to 125 . Symbols: solid circle $(\bullet)$ : absorbance at $220 \mathrm{~nm}\left(\mathrm{~A}_{220}\right)$ of upper mobile phase; opened circle $(\circ)$ : $\mathrm{A}_{220}$ of lower stationary phase; black bar: GTF activity $\left(\mathrm{A}_{550}\right)$ of each fraction.

Table 5. Purity and Recovery of GTF at Different Purification Steps

\begin{tabular}{|c|c|c|c|c|c|}
\hline & $\begin{array}{l}\text { Total Protein } \\
\text { (mg) }\end{array}$ & $\begin{array}{c}\text { Total Activity } \\
\text { (mU) }\end{array}$ & $\begin{array}{c}\text { Specific Activity }^{* 3} \\
(\mathrm{mU} / \mathrm{mg})\end{array}$ & $\begin{array}{c}\text { Recovery }^{* 4} \\
\text { (\%) }\end{array}$ & $\begin{array}{c}\text { Purity }^{* 5} \\
\text { (Fold) }\end{array}$ \\
\hline Cell culture medium $(500 \mathrm{ml})$ & 58.3 & 7.91 & 0.14 & 100 & 1 \\
\hline CCC fractions (18 ml) & 0.4 & 5.51 & 13.51 & 70 & 100 \\
\hline hydroxyapatite chromatography fractions $(5 \mathrm{ml})$ & 0.07 & 2.56 & 36.81 & 32 & 272 \\
\hline
\end{tabular}

${ }^{1}$ Total protein content (mg) was measured by Bradford protein assay.

$2^{*}$ One unit $(1 \mathrm{U})$ of GTF was defined as the amount of enzyme required to converts $1.0 \mathrm{mmol}$ of glucose residue from the sucrose molecule into WIG per minute. The amount of WIG was measured by phenol-sulfate method.

${ }^{3 *}$ Specific activity was expressed in the ratio of total activity $(\mathrm{mU})$ per total protein $(\mathrm{mg})$.

$4^{*}$ Recovery of GTF was expressed in the percentage ratio of the total activity of each fraction per that of SS culture medium.

${ }^{5 *}$ Purification efficient was expressed in the ratio of the specific activity of each fraction per that of SS culture medium. 
phase and open circles indicate those in the stationary lower phase of the fractionated column contents. The large peak with a front shoulder eluted from frs. 35 to 75 (105 ml -225 $\mathrm{ml}$ retention volume) shows no GTF enzyme activity, indicating that it contains almost all protein components other than GTF in the cell-lysate. The bar graphs in the chromatogram indicate the GTF activities which are, as expected from their $\mathrm{K}$ values (Table 3), solely found in frs. 115-125 (345 $\mathrm{ml}-375 \mathrm{ml}$ retention volume) obtained from the column contents. These results indicate that the effective separation of GTF from the bacterial cell-lysate was achieved by this CCC method.

However, these CCC fractions contain high concentrations of high dextran T500 which cannot be easily removed by dialysis or ultrafiltration. Therefore, a hydroxyapatite chromatography (HA) was complementarily used for the elimination of these polymers from the CCC fraction as described above (chromatogram not shown).

Fig. (9) shows SDS-PAGE profiles of the S. mutans celllysate and CCC fractions before and after separationg with the HA column. GTF appears as a band corresponding to its molecular mass of about $150 \mathrm{kDa}$ on the gel. The lane of CCC fractions (frs. 110-125) proved that GTF was clearly separated from the other proteins in cell-lysate by CCC in the one-step operation. In the lanes of HA fractions, GTF was only detected in the eluate with $500 \mathrm{mM}$ phosphate buffer. The results of the SDS-PAGE analysis clearly indicate that the GTF was completely isolated from the $S$. mutans cell-lysate.

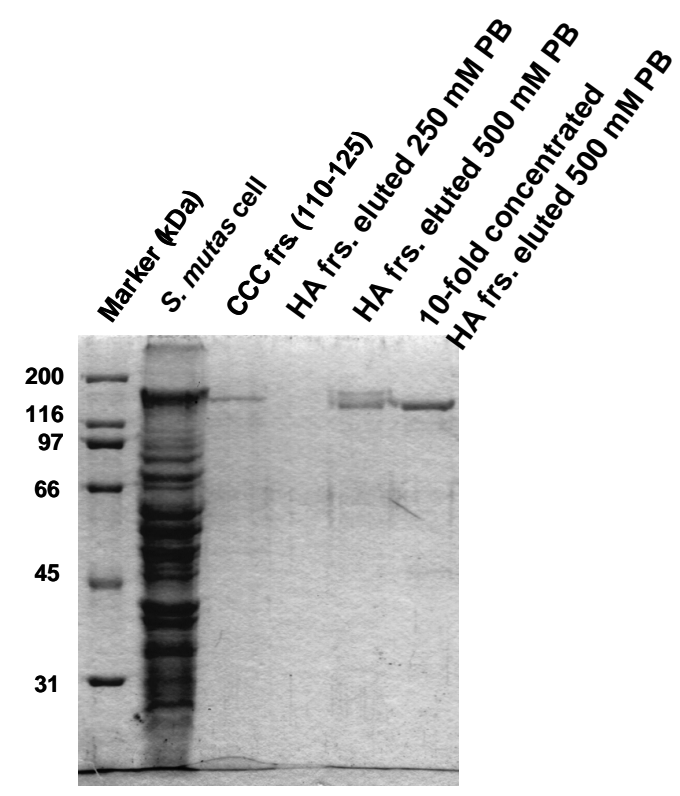

Fig. (9). SDS- 10\% polyacrylamide gel electrophoretic profile of $\mathrm{CCC}$ and HA fractions.

Table 6 shows the purity and recovery rate of GTF in each fraction at two purification steps before and after HA chromatography. Through the GTF purification process, the purity of GTF was markedly increased while maintaining a reasonable recovery rate. In the final product the GTF purity in the concentrated HA fractions was increased about 87 times as that in the cell-lysate with a good recovery rate of about $79 \%$ through this two-step purification process.
Table 6. Specificity and Recovery of GTF Purification from S. mutans Cell-Lysate

\begin{tabular}{|l|c|c|c|c|c|}
\hline $\begin{array}{c}\text { GTF } \\
\text { Fraction } \\
\text { (Volume) }\end{array}$ & $\begin{array}{c}\text { Total } \\
\text { Protein } \\
\text { (Mg) }\end{array}$ & $\begin{array}{c}\text { Total } \\
\text { GTF } \\
\text { Activity } \\
\text { (mU) }\end{array}$ & $\begin{array}{c}\text { Specific } \\
\text { Activity } \\
\text { (mU/mg) }\end{array}$ & $\begin{array}{c}\text { Recovery } \\
\text { (\%) }\end{array}$ & $\begin{array}{c}\text { Purity }^{* 3} \\
\text { (Fold) }\end{array}$ \\
\hline \hline $\begin{array}{l}\text { S. mutans } \\
\text { cell-lysate } \\
(10 \mathrm{~mL})\end{array}$ & 11.350 & 3.302 & 0.291 & 100 & 1 \\
\hline $\begin{array}{l}\text { Fr. after } \\
\begin{array}{l}\text { CCC }(25 \\
\text { mL) }\end{array}\end{array}$ & 0.457 & 2.845 & 6.23 & 86 & 21.4 \\
\hline $\begin{array}{l}\text { Fr. after } \\
\text { HA } \\
(5 \mathrm{~mL})\end{array}$ & 0.103 & 2.604 & 25.3 & 79 & 86.9 \\
\hline
\end{tabular}

${ }^{1}$ Specific activity was expressed in the ratio of total GTF activity (mU) per total protein $(\mathrm{mg})$.

${ }^{* 2}$ Recovery of GTF was expressed in the \% ratio of the total GTF activity of each fraction per that of $S$. mutans cell-lysate.

${ }^{* 3}$ Purification efficient was expressed in the ratio of the specific activity of each fraction per that of $S$. mutans cell-lysate.

6.3.2. CCC Using PEG 3350-Dextran T40 Two Phase System

As described above, GTFs from $S$. sobrinus culture medium and $S$. mutans cell-lysate were purified by CCC using the cross-axis CPC with PEG 8000-dextran T500 solvent systems. After CCC purification, these polymers were removed from CCC fractions by hydroxyapatite chromatography. However, due to irreversible adsorption onto the hydroxyapatite column packing materials, GTFs were lost about $54 \%$ from $S$. sobrinus and $10 \%$ from $S$. mutans samples.

We have developed new aqueous-aqueous two-phase systems composed of relatively low molecular weight of PEGs and dextrans, which are easily removed from the CCC fractions by ultrafiltration in a short period time.

Fig. (10) shows a CCC chromatogram of GTF from $S$. mutans cell-lysate obtained by the cross-axis CPC using $7.5 \%(\mathrm{w} / \mathrm{w})$ PEG $3350-10.0 \%(\mathrm{w} / \mathrm{w})$ dextran T40-10 mM potassium phosphate buffer $(\mathrm{pH} 9.0)$. The solid circles indicate the absobance at $220 \mathrm{~nm}$ in the eluted upper phase. The solvent front emerged at 41 fraction and two peaks eluted from the column with upper phase (frs. 41 to 90). These peaks show no GTF enzyme activity, indicating that the first peak (frs. 41-48) contain almost all protein component other than GTF and second peak (frs. 50-90) contain impurities in the cell-lysate. After CCC run stop at fr. 90, the column contents was emptied by air pressure and fractionated from frs. 91 to 155 . The solid triangles indicate the absorbance at 220 $\mathrm{nm}$ in the stationary lower phase of the column contents and the bar graphs indicate the GTF enzyme activities in the column contents. As expected from the K value, the GTF activities in the CCC fractions are solely found in frs. 140-155 collected from the column contents.

The GTF fractions obtained by CCC contained a large quantity of PEG 3350 and dextran T40. In this situation it is very difficult to analyze the CCC fraction by SDS-PAGE, because the purified GTF band is smeared by PEG or dextran present in the fraction. Therefore, it is necessary to remove both PEG 3350 and dextran T40 before application to the gel. 


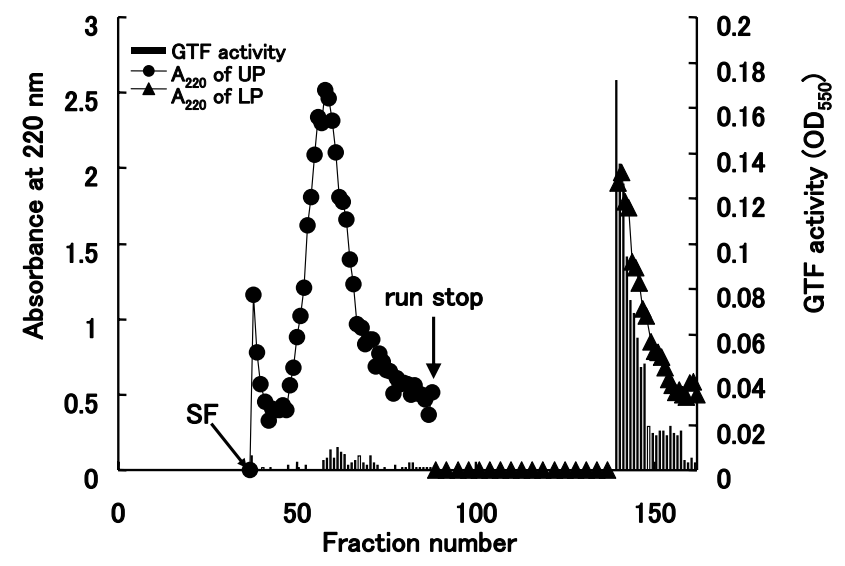

Fig. (10). Separation profile of Streptococcus mutans (SM) celllysate by counter-current chromatography using cross-axis coil planet centrifuge. Experimental conditions: apparatus: type-XL cross-axis coil planet centrifuge with a pair of multilayer coil columns of $2.6 \mathrm{~mm} \mathrm{I}$. D. and $110 \mathrm{ml}$ total capacity; solvent system: 7.5\% PEG 3350-10\% dextran T40-10 mM potassium phosphate at pH 9.0; stationary phase: dextran-rich lower phase; mobile phase: PEG 3350-rich upper phase; $5 \mathrm{~g}$ of SM cell-lysate containing $0.45 \mathrm{~g}$ PEG 3350, $0.61 \mathrm{~g}$ dextran T40; flow rate: $0.5 \mathrm{ml} / \mathrm{min}$; revolution speed: $400 \mathrm{rpm}$; fractionation: $3 \mathrm{ml}$ per tube; $\mathrm{SF}=$ solvent front.

Relatively low molecular weight of PEG 3350 and dextran T40 were removed by ultrafiltration. After CCC purification of GTF, CCC fractions 41-48, 50-90 and 140-155 were diluted with 5 -fold volume of $10 \mathrm{mM}$ potassium phosphate buffer at 7.0. About 120-225 ml-volume of diluted sample solution was ultrafiltered with a large diameter $(63.5$ $\mathrm{mm})$ ultrafiltration membrane. Fig. (11) shows the SDSPAGE profile of the sample solutions obtained by ultrafiltration. The concentrated fractions from 140 to 155 contained GTF corresponding to the molecular weight of $150 \mathrm{kDa}$. The specific activity of GTF after concentrated by ultrafiltration was about 100 times high activity compared with that in the cell-lysate and the recovery of the enzyme from CCC fraction was over $95 \%$ as estimated by enzymatic activities.

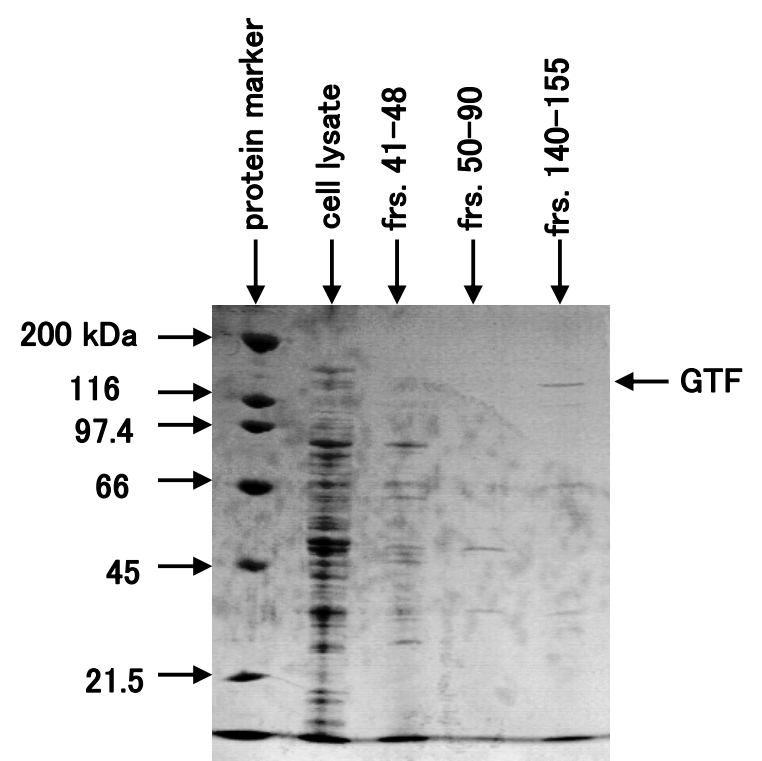

Fig. (11). 10\% SDS polyacrylamide gel electrophoresis profile of $\mathrm{CCC}$ fractions.
6.4. Purification of Maltose Binding Protein Tagged Histone Deacetylase (MBP-HDAC)

\subsubsection{Purification of MBP-HDAC from Escherichia coli Cell-Lysate}

The purification of maltose binding protein tagged histone deacetylase (MBP-HDAC), which would be precipitated out due to a high salt concentration of the two-phase system, such as $16 \%$ PEG $1000-12.5 \%$ potassium phosphate system, was performed using the solvent system composed of relatively low molecular weight of PEG and dextran which are easily removed from the CCC fractions by ultrafiltration.

Fig. (12) shows a CCC chromatographic purification of MBP-HDAC from E. coli cell-lysate obtained by the crossaxis CPC using 7.0\% (w/w) PEG 3350-10.0\% (w/w) dextran T40-10 mM potassium phosphate buffer ( $\mathrm{pH} 9.0)$. The solvent front emerged at the 33rd fraction and two peaks were eluted from the column with the upper mobile phase (frs. 3353). After 53 fractions were collected, CCC run was stopped and the column contents were fractionated by cassette tube pump passing pressured air through the column to obtain frs. 54 to 60 .

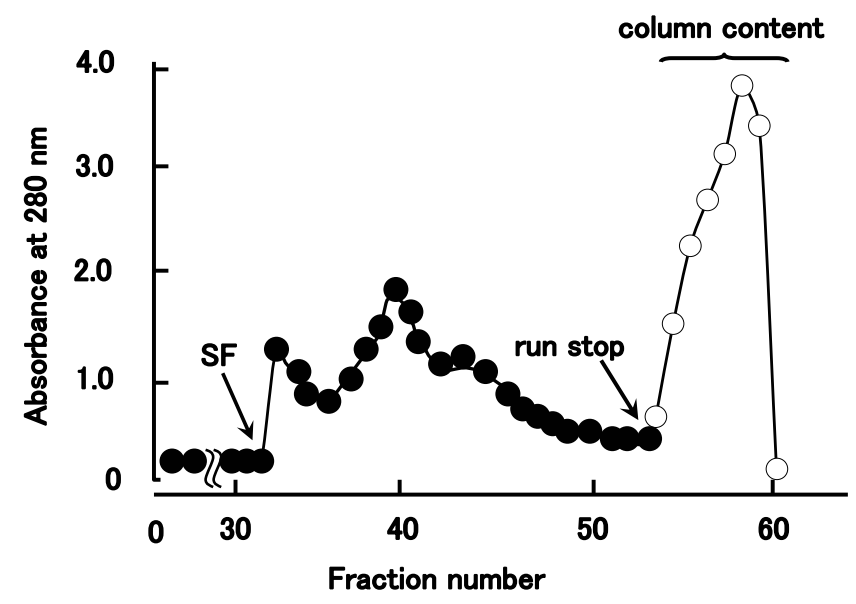

Fig. (12). Selective purification of HDAC from an E. coli celllysate by counter-current chromatography using the cross-axis CPC. Experimental conditions: apparatus: type-XL cross-axis coil planet centrifuge with a pair of multilayer coil columns of $2.6 \mathrm{~mm}$ I. D. and $110 \mathrm{ml}$ total capacity; solvent system: $7.0 \%$ PEG 3350$10 \%$ dextran $\mathrm{T} 40-10 \mathrm{mM}$ potassium phosphate at $\mathrm{pH} 9.0$; stationary phase: dextran-rich lower phase; mobile phase: PEG 3350-rich upper phase; $5 \mathrm{~g}$ of SM cell-lysate containing $0.45 \mathrm{~g}$ PEG 3350, $0.61 \mathrm{~g}$ dextran T40; flow rate: $0.25 \mathrm{ml} / \mathrm{min}$; revolution speed: 400 rpm; fractionation: $3 \mathrm{ml}$ per tube; $\mathrm{SF}=$ solvent front.

Fig. (13) shows the SDS-PAGE profile of the CCC fractions obtained by ultrafiltration. The concentrated fractions from 33 to 35 contained no protein. The fraction eluted with upper PEG-rich phase, fractions from 39 to 41 and 43 to 45 contained MBP, tag protein, and other impurities. On the other hand, fractionated column contents, fractions 55 to 60 contained only HDAC. It appears that the MBP tag was digested from the fusion protein, HDAC, during CCC separation and a native enzyme was retained in the column contents. 


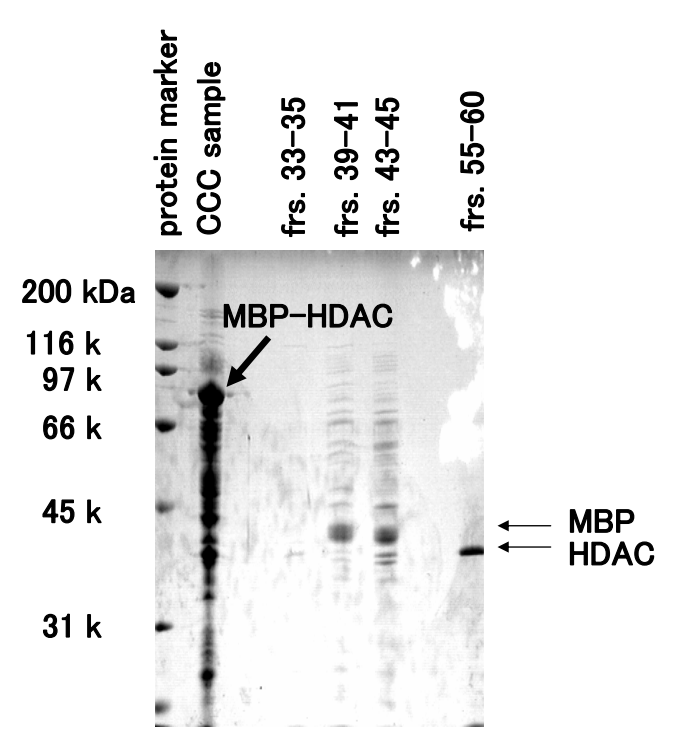

Fig. (13). $10 \%$ SDS polyacrylamide gel electrophoresis profile of $\mathrm{CCC}$ fractions.

\subsubsection{Determination of Enzyme Activity of HDAC by HPLC}

The $\mathrm{NAD}^{+}$dependent HDAC activity in the column content was confirmed by an reversed-phase HPLC-based in vitro assay using an acetylated peptide as a synthetic substrate. The column contents including HDAC were mixted with acetylated peptide and $\mathrm{NAD}^{+}$was added. The mixture was incubated at $37^{\circ} \mathrm{C}$ for $20 \mathrm{~min}$. The HPLC chromatograms before and after incubation were shown in Fig. (14).

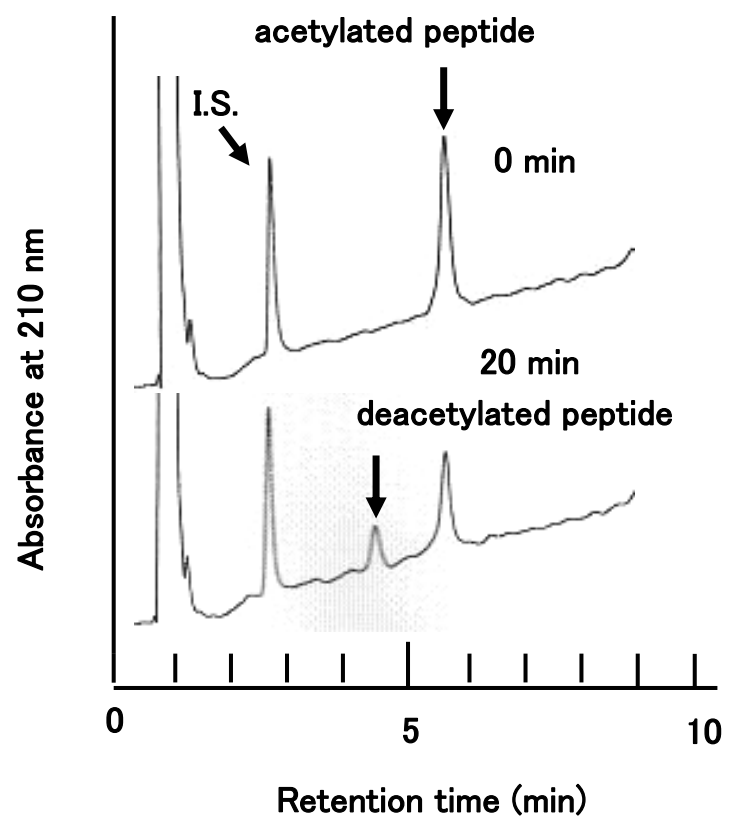

Fig. (14). RP-HPLC determination of deacetylation process of histone deacetylase. Chromatographic conditions: column: Chromolith Performance RP-18e (100 mm x $4.6 \mathrm{~mm} \mathrm{I.} \mathrm{D.);} \mathrm{sample:} \mathrm{The} \mathrm{mix-}$ ture of CCC fractions contained HDAC, acetyl peptide and $\mathrm{NAD}^{+}$ before and after incubation at $37^{\circ} \mathrm{C}, 10 \mu \mathrm{l}$; gradient elution: solvent A $(0.1 \%$ TFA : acetonitrile, $9: 1)$, solvent B $(0.1 \%$ TFA : acetonitrile, $5: 5$ ), solvent A $100 \%$ to $90 \%$ and solvent B 0 to $10 \%$ from 0 min to $10 \mathrm{~min}$; flow rate : $3.0 \mathrm{ml} / \mathrm{min}$; detection: absorbance at 210 $\mathrm{nm}$.
After $20 \mathrm{~min}$ incubation, deacetylated peptide peak was emerged at the retention time of $4.7 \mathrm{~min}$. The results indicated that the enzyme activity of HDAC was well preserved after CCC purifcation.

\section{CONCLUSION}

In conclusion, the complementary use of the batch extract in the aqueous polymer two phase system and CCC is a very useful method for the purification of GTF, which released in the large quantities of the culture medium of $S$. sobrinus. The aqueous two-phase systems composed of 7.5\% PEG 3350 and $10.0 \%$ dextran T40 is very useful for the purification of GTF from $S$. mutans cell-lysate by CCC using the cross-axis $\mathrm{CPC}$, since these polymers are easily removed from the $\mathrm{CCC}$ fractions by ultrafiltration. Consequently, the method eliminates the hydroxyapatite chromatography procedure and yields high recovery of GTF for a short time. The present polymer phase system is also very useful for purification of MBP-HDAC from E. coli cell-lysate by CCC. During CCC, the tag protein, MBP, was digested and pure HDAC was obtained with an enzymatic activity. The CCC using the polymer phase system composed of relatively low molecular weight PEG and dextran may be useful for purification of various other fusion proteins.

\section{REFERENCES}

[1] Albertsson, P. A. Partition of cell particles and macromolecules, 3rd ed. Wiley \& Sons: New York, 1986.

[2] Crag, L. C.; Post, O. Anal. Chem., 1949, 21, 500.

[3] Crag, L. C.; Hausmann, W.; Ahrens, E. H.; Harfenist, E. J. Anal. Chem., 1951, 23, 1236.

[4] Ito, Y.; Bowman, R. L. Science, 1970, 167, 281.

[5] Ito, Y.; Bowman R. L. J. Chromatogr. Sci., 1970, 8, 315.

[6] Tanimura, T.; Pisano, J. J.; Ito, Y.; Bowman, R. L. Science, 1970, $169,54$.

[7] Ito, Y.; Bowman, R. L. Anal. Chem., 1971, 43, 69A.

[8] Ito, Y.; Bowman, R. L. Science, 1972, 173, 420.

[9] Hurst, R. E.; Ito, Y. Clin. Chem., 1972, 18, 814.

[10] Ito, Y.J. Chromatogr., 1981, 207, 161.

[11] Ito, Y.; Sandlin, J.; Bowers, W. G. J. Chromatogr., 1982, 244, 247.

[12] Ito, Y.; Kitazume, E.; Bhatnagar, M. J. Chromatogr., 1991, 538, 59.

[13] Ito, Y.; Kitazume, E.; Slemp, J. L. J. Chromatogr., 1991, 538, 81.

[14] Shibusawa, Y.; Ito, Y. J. Chromatogr., 1991, 550, 695.

[15] Shibusawa, Y.; Ito, Y.; Ikewaki, K.; Rader, D. J.; Brewer, B. J. Chromatogr., 1992, 596, 118.

[16] Shibusawa, Y.; Chiba, T.; Matsumoto, U.; Ito Y. Modern Countercurrent Chromatography, Conway, W. D.; Petroski, R. J., Eds.;ACS Monographs, American Chemical Society, Washington D. C., 1995; Ch. 11, pp. 119-128.

[17] Shibusawa, Y.; Mugiyama, M.; Matsumoto, U.; Ito Y. J. Chromatogr. B, 1995, 664, 295.

[18] Shibusawa, Y.; Hosojima, T.; Nakata, M.; Shindo, H.; Ito, Y. $J$ Liq. Chromatogr. Rel. Technol., 2001, 24, 1733.

[19] Shibusawa, Y.; Eriguchi, Y.; Ito, Y. J. Chromatogr. B, 1997, 696, 25 .

[20] Shibusawa, Y.; Misu, N.; Shindo, H.; Ito, Y. J. Chromatogr. B, 2001, 776, 183.

[21] Shibusawa, Y.; Fujiwara, T.; Shindo, H.; Ito, Y. J. Chromatogr. B, 2004, 799, 239.

[22] Lee, Y. W.; Shibusawa, Y.; Chen, F. T.; Myers, J.; Schooler, J. M.; Ito, Y. J. Liq. Chromatogr., 1992, 15, 2831.

[23] Shibusawa, Y.; High-Speed Countercurrent Chromatography, Ito Y.; Conway W. D., Eds.; Wiley \& Sons: New York, 1996, Ch. 13, pp. 385-414.

[24] Shibusawa, Y.; Ino, Y.; Kinebuchi T.; Shimizu, M.; Shindo, H.; Ito Y. J. Chromatogr. B, 2003, 793, 275.

[25] Shibusawa, Y.; Ito, Y. J. Liq. Chromatogr., 1992, 15, 2787.

[26] Yanagida, A.; Isozaki, M.; Shibusawa, Y.; Shindo, H.; Ito, Y. J. Chromatogr. B, 2004, 805, 155. 
[27] Shibusawa, Y.; Isozaki, M.; Yanagida, A.; Shindo, H.; Ito, Y. $J$. Liq. Chromatogr. Rel. Technol., 2004, 27, 2217.

[28] Shibusawa, Y.; Takeuchi, N.; Sugawara, K.; Yanagida, A.; Shindo, H.; Ito, Y. J. Chromatogr. B, 2006, 844, 217.

[29] Shibusawa, Y.; Takeuchi, N.; Tsutsumi, K.; Nakano, S.; Yanagida, A.; Shindo, H.; Ito, Y. J. Chromatogr. A, 2007, 1151, 158.

[30] Borra, M. T.; O’Neill, F. J.; Jackson, M. D.; Marshall, B.; Verdin, E.; Foltz, K. R.; Denu, J. M. J. Biol. Chem., 2002, 277, 12632.

[31] Yanagida, A.; Kanda, T.; Tanabe, M.; Matsudaira, F.; Cordeiro, J. G. O. J. Agric. Food Chem., 2000, 48, 5666.
[32] Tagashira, M.; Uchiyama, K.; Yoshimura, T.; Shirota, M.; Uemitsu, N. Biosci. Biotechnol. Biochem., 1997, 61, 332.

[33] Shimamura, A.; Tsumori, H.; Musaka, H. Biochim. Biophys. Acta, 1982, 702, 72 .

[34] Borra, M. T.; Denu, J. M. Methods Enzymol., 2003, 376, 171.

[35] Shibusawa, Y.; Ito, Y. J. Liq. Chromatogr., 1992, 15, 2787.

[36] The Japanese Pharmacopoeia 15 th ed., 2006, p. B-320.

[37] Bhatnagar, M.; Oka, H.; Ito, Y. J. Chromatogr. 1989, 463, 317.

[38] Shinomiya, K.; Menet, J. M.; Fales, H. M.; Ito, Y. J. Chromatogr. 1993, 644, 215.

[39] Laemmli, U. K. Nature, 1970, 227, 680. 